\title{
Associations between housing and management practices and the prevalence of lameness, hock lesions, and thin cows on US dairy operations
}

\author{
A. E. Adams, ${ }^{*} \dagger^{1}$ J. E. Lombard, $\dagger^{2}$ C. P. Fossler, $\dagger$ I. N. Román-Muñiz, ${ }^{*}$ and C. A. Kopral $\dagger$ \\ *Department of Animal Sciences, Colorado State University, Fort Collins 80523 \\ TUSDA-APHIS-VS Center for Epidemiology and Animal Health, National Animal Health Monitoring System, Fort Collins, CO 80526
}

\begin{abstract}
The objective of this study was to determine the association among different housing and management practices on the prevalence of lameness, hock lesions, and thin cows on US dairy operations. This study was conducted as part of the National Animal Health Monitoring System's Dairy 2014 study, which included dairy operations in 17 states. Size categories were assigned as follows: small (30-99 cows), medium (100-499 cows), and large ( $\geq 500$ cows). Trained assessors visited 191 dairy operations from March through July 2014 and recorded locomotion and hock scores (on a 3-point scale), and the number of thin cows (body condition score $\leq 2.25$ ) from a total of 22,622 cows (average 118 cows per farm). The majority of cows (90.4\%) were considered to be sound (locomotion score $=1$ ), $6.9 \%$ were mild/moderately lame (locomotion score $=2$ ), and $2.7 \%$ were severely lame (locomotion score $=3$ ). Similarly, most cows $(87.3 \%)$ had no hock lesions (hock score $=1$ ), $10.1 \%$ had mild lesions (hock score $=2$ ), and $2.6 \%$ had severe hock lesions (hock score $=3$ ). A low percentage of cows $(4.2 \%)$ were thin. Univariate comparisons were performed using PROC LOGLINK, which accounts for study design and weighting. Variables meeting the univariate screening criterion of $P<$ 0.20 were eligible for entry into multivariable models. Statistical significance in the multivariable models was declared at $P<0.05$. Large operations had a lower within-herd prevalence of cows with locomotion score $\geq 2$ and locomotion score $=3$ compared with small or medium-sized operations. Operations on which cows were kept primarily on pasture had a lower percentage of locomotion score $=3$ than those housed in freestall
\end{abstract}

Received May 26, 2016.

Accepted November 18, 2016.

${ }^{1}$ Current address: School of Agriculture, Sustainability, Business and Entrepreneurship, Morrisville State College, Morrisville, NY 13408.

${ }^{2}$ Corresponding author: Jason.e.lombard@aphis.usda.gov or open/dry lot operations. The use of sand bedding was associated with a lower within-herd prevalence of locomotion score $\geq 2$ than straw/hay or dry/composted manure as the primary bedding material. Sand bedding was also associated with a lower within-herd prevalence of locomotion score $=3$ than other bedding types except for rubber mats or mattresses. Operations that housed cows in an open/dry lot had a lower percentage of hock score $\geq 2$ and hock score $=3$ than other housing types. Providing sprinklers for heat abatement and having a nutritionist balance rations for cows was associated with a lower percentage of thin cows. Results from this study highlight management practices that may reduce the prevalence of lameness, hock lesions, and thin cows on dairy operations in the United States. Key words: dairy cow, lameness, hock lesions, body condition

\section{INTRODUCTION}

Lameness is a leading welfare concern in the dairy industry, mainly because lame animals are in pain (O'Callaghan et al., 2003; Rushen et al., 2007). The mean prevalence of lameness on dairies in the United States is reported to range from 13 to $55 \%$ (von Keyserlingk et al., 2012; Hoffman et al., 2014; Cook et al., 2016), indicating that roughly a quarter to half of dairy cows in the United States are in pain. In addition to its impact on welfare, lameness has been shown to result in decreased milk production (Warnick et al., 2001; Juarez et al., 2003; Hernandez et al., 2005), reduced reproductive efficiency (Hernandez et al., 2001; Garbarino et al., 2004), and increased culling (Sprecher et al., 1997; Booth et al., 2004). Dairy characteristics, such as housing type, bedding material, and flooring design, have been shown to affect dairy cow lameness. Cows in compost barns have been shown to have a lower prevalence of lameness compared with cows in freestall barns (Lobeck et al., 2011). Similarly, cows that were housed in freestall barns with access to pasture had a lower prevalence of lameness compared with those housed in freestall barns with no access to pasture (17 vs. 39\%; 
Haskell et al., 2006). Herds using deep sand bedding had a lower prevalence of lameness than herds using mattress-bedded stalls (Cook, 2013) or those using sawdust-bedded stalls (Chapinal et al., 2013). Housing cows on concrete has also been associated with dairy cow lameness; a study by Vanegas et al. (2006) found that cows housed on concrete were 5 times more likely to be diagnosed as lame as those housed on rubber mats over concrete.

Hock lesions are a common leg injury and welfare concern for dairy cattle (Whay et al., 2003). Housing characteristics can affect the occurrence of hock lesions in dairy cows. In a study of dairy cows on farms in New York, Oregon, and Wisconsin, cows that had access to pasture had fewer hock lesions compared with cows that had no pasture access (Bergman et al., 2014). A Canadian study reported a hock lesion prevalence of $56 \%$ in cows housed in tiestall operations (Nash et al., 2016), compared with prevalences of 47 and $50 \%$ reported in freestall operations in Canada and Wisconsin, respectively (Zaffino Heyerhoff et al., 2014; Cook et al., 2016). Multiple studies have illustrated the benefits of deep sand bedding for reducing the prevalence of hock lesions. In a survey of 297 freestall operations in the United States, operations that used rubber mats or mattresses as bedding had a higher percentage of cows with severe hock lesions than operations that used sand bedding (Lombard et al., 2010). Similar results have been found in other studies, with the use of rubber mats or mattresses resulting in an increase in hock lesions compared with sand-bedded stalls (Weary and Taszkun, 2000; Fulwider et al., 2007; Lobeck et al., 2011).

Body condition scores are used to gauge the amount of muscle and fat on a dairy cow, with low values representing under-conditioned or emaciated cows, and high values representing over-conditioned or obese animals (Wildman et al., 1982; Ferguson et al., 1994). There is concern from the public that the welfare of underconditioned dairy cows is compromised (Roche et al., 2009), whereas multiple studies suggest that the health of over-conditioned dairy cows may suffer (Markusfeld, 1985; Gillund et al., 2001). Over-conditioned cows are at an increased risk of metabolic diseases following calving, including milk fever (Roche and Berry, 2006), and ketosis (Gillund et al., 2001; Ingvartsen, 2006). In contrast, a study by Hoedemaker et al. (2009) illustrated an association between BCS and lameness, with thin animals more likely to be lame. Multiple herd-level and cow-level factors may affect the body condition of cows, including whether or not all lactating cows are fed the same ration, as well as overall production level. The stage of lactation of a cow has been shown to influence
BCS. As cows are not able to consume enough feed to meet their energy requirements during early lactation, the BCS profiles of cows after calving have been shown to be a mirror image of the milk production curve, with BCS declining as milk production increases (Roche et al., 2009).

A wide range of housing and management systems are used on dairy operations and some may negatively affect cow welfare, specifically lameness, the occurrence of hock lesions, and low BCS. The USDA's National Animal Health Monitoring System (NAHMS) conducts national surveys to collect information on the health and management of domestic livestock species and, in 2014, a study was conducted to collect information about the US dairy industry (USDA, 2014). The information reported here is a component of the NAHMS 2014 Dairy study. During the needs assessment phase of the 2014 study, key industry stakeholders, including university, extension, and dairy personnel, requested that the study include a national estimate of the prevalence of lameness because one was not available. In addition to providing a national estimate, it was requested that the study evaluate different management practices and housing types and their effects on lameness. Estimates generated from this national study could also be used to inform evaluation programs, such as the National Milk Producers Federation's Farmers Assuring Responsible Management (FARM) program. The objective of this study was to determine the association between different housing and management practices and estimate the prevalence of lameness, hock lesions, and thin cows on US dairy operations.

\section{MATERIALS AND METHODS}

\section{Study Design}

The USDA's National Agricultural Statistics Service (NASS) Cattle Report was used to determine states for inclusion in the NAHMS Dairy 2014 study (USDA, 2013), with the goal of including states that accounted for at least $70 \%$ of both dairy operations and dairy cattle in the United States. Seventeen states were chosen for inclusion in the study, representing $80.5 \%$ of dairy operations and $81.3 \%$ of dairy cows in the United States. The states were categorized into 2 regions (West: California, Colorado, Idaho, Texas, Washington; East: Indiana, Iowa, Kentucky, Michigan, Minnesota, Missouri, New York, Ohio, Pennsylvania, Vermont, Virginia, Wisconsin). Then, NASS used a sampling frame and selected a stratified random sample of dairy operations within each state to participate in the study. Herd sizes were defined as very small (1 to 29 cows), 
small (30 to 99 cows), medium (100 to 499 cows), and large ( $\geq 500$ cows).

Enumerators contracted by NASS visited dairy operations in January 2014 to complete the survey for producers with $\geq 30$ dairy cows (phase I of NAHMS Dairy 2014). During the same period, operations with at least 1 dairy cow but $<30$ cows were mailed an abbreviated version of the questionnaire which consisted of a subset of questions that were applicable to very small operations. To be eligible for phase II of the study, operations had to have $\geq 30$ adult cows and have completed phase I of the study. The USDA's Veterinary Services personnel or state animal health staff visited dairy operations from March through July 2014 to complete the phase II survey. Operations that completed both phases of the study were eligible for the cow evaluation component of the study (Figure 1).

The survey for phase I of the study included 171 questions for small, medium-sized, and large operations; the mail-in version included 68 questions for very small operations. The survey collected information regarding cow and heifer inventory, operation type (e.g., organic, grazing, conventional), productivity, housing, preventive practices, management of nonambulatory cattle, and euthanasia practices. A total of 1,261 operations completed phase I. The survey for phase II included

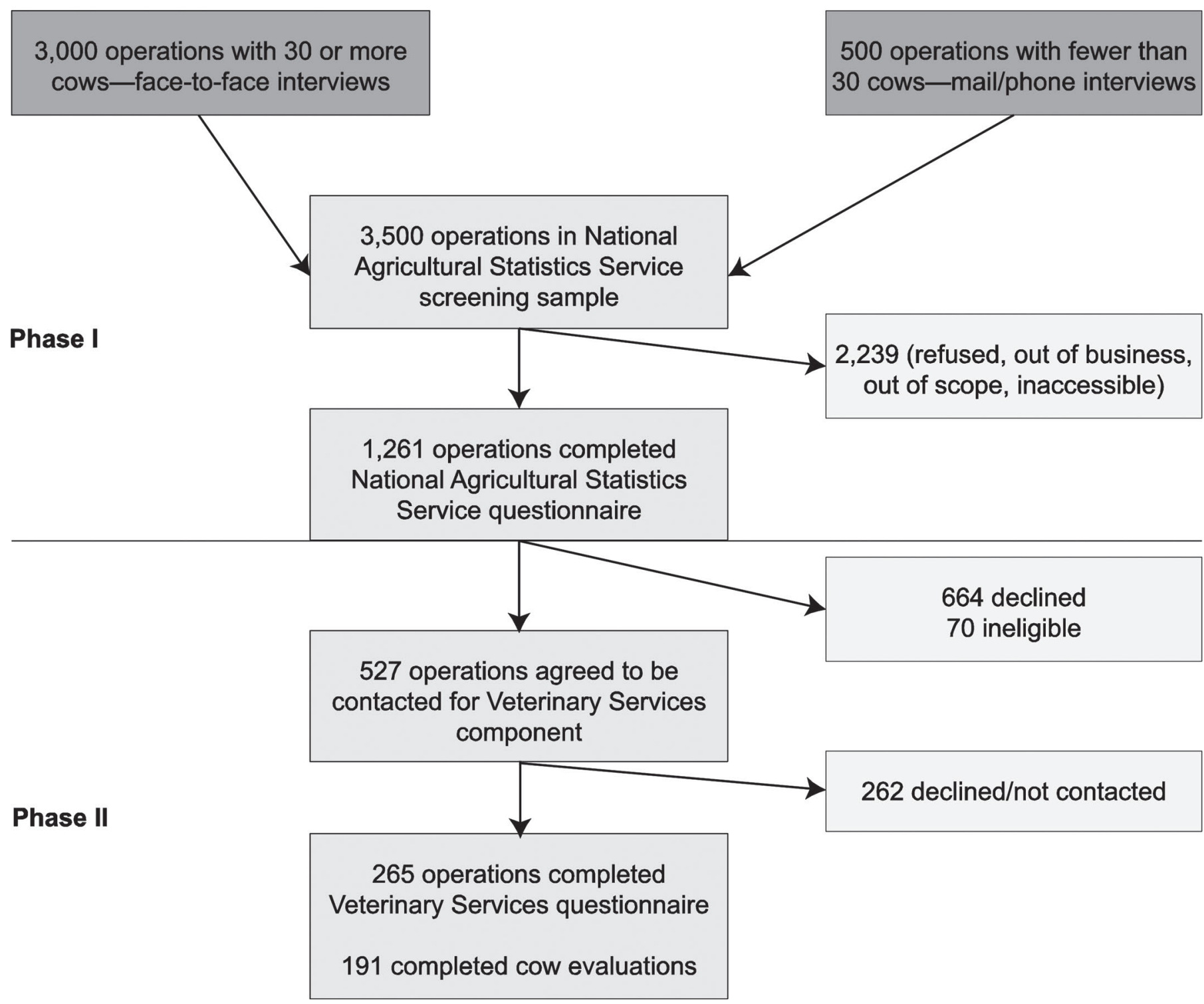

Figure 1. Flowchart of participation in the US National Animal Health Monitoring System's Dairy 2014 study (USDA, 2014). 
144 questions and collected information regarding milking procedures, employee training, morbidity estimates, lameness prevention and management, culling, and mortality. Of the 1,191 operations that were eligible for participation in phase II (70 operations from phase I had $<30$ cows), 265 operations completed the phase II questionnaire. Both questionnaires are available on the NAHMS website (USDA, 2014). Questionnaires were designed to take no more than $2 \mathrm{~h}$ to complete and were pretested in multiple states to evaluate the validity and clarity of questions. Problematic questions were revised to improve validity and the ease of survey administration. Staff of NASS and USDA's Veterinary Services received training before administering the questionnaires. Survey instruction manuals were developed to be used while administering the surveys, providing clarification for the terms and procedures referenced in the questionnaires. Before each visit, owners were provided with a list of information for them to gather before the visit to expedite the interview process and assist in answering the questionnaire.

\section{Cow Evaluations}

All data were recorded on an evaluation form (USDA, 2014). Evaluators were asked to score all cows on operations with 100 cows or fewer, and to select 1 or 2 pens to score on operations with more than 100 cows. On operations where 1 or 2 pens were scored, it was up to the evaluator to determine which pen(s) to score, but it was highly recommended to score the high-production pen. Evaluators recorded the number of cows scored on each operation, the group of cows scored (e.g., entire herd, high production pen), the surface that cows were scored on (i.e., concrete, dirt/other), and the condition of the scoring surface (i.e., dry, wet/snow/ice).

Cows were evaluated for locomotion, hock, and body condition scores by veterinary medical officers or animal health technicians. Each evaluator was trained by coordinators in each state, with training consisting of a video and reference sheets to use for locomotion, hock, and body condition scoring. A 3-point locomotion scoring (LS) system was developed specifically for use in this study, with collaboration from researchers in the area of dairy cow lameness in the United States and Canada (USDA, 2014). The scoring system was defined as follows: $1=$ sound: no visible gait abnormality to a very slight gait abnormality; freedom of movement with normal strides; older cows may have a slight arch, may appear a little stiffer, and may walk slower, but there is no obvious discomfort; $2=$ mild or moderately lame: visible gait abnormality, which may include shortened stride length, head bob, and/ or arching of the back; cow appears uncomfortable and walks abnormally; the affected limb is/may not be obvious; and 3 = severely lame: obvious gait abnormality, which may include shortened stride length, prominent head bob, and/or pronounced arching of the back, with the cow favoring one or more limbs; cows will be hesitant or refuse to bear weight on the affected limb, and walking will be extremely difficult; these cows appear to be in pain. A lameness training video was viewed by evaluators that showed examples of cows with different locomotion scores. The video described which features (e.g., stride length, head bob, arched back) to focus on for the lameness evaluation and also had a self-assessment section where evaluators could score cows and compare their results with those of lameness experts.

Hock scoring (HS) was conducted using a 3-point system developed by Cornell University (2009), with 1 = no swelling or hair loss, $2=$ no swelling but hair loss, and 3 = swelling and hair loss. To make the process easier, evaluators were asked to record only the number of cows that received a score of 2 or 3 for either locomotion or hock scoring and then subtract that from the total number of cows scored (either on the farm or in the pen) to determine the number cows that scored a 1 for locomotion or hock lesions. Body condition scoring was conducted using a 5 -point system developed by Elanco (Elanco Animal Health, Greenfield, IN), which was adapted from the scoring systems developed by Wildman et al. (1982) and Ferguson et al. (1994). The scoring system ranges from $1=$ emaciated to $5=$ obese. Evaluators were asked to record the number of cows with a BCS $\leq 2.25$, representing a thin cow, and then subtract that from the total number of cows scored to determine the number of cows with adequate BCS. To identify cows with a BCS $\leq 2.25$, evaluators were trained to evaluate the amount of fat on the pins and the corrugations on the short ribs. If no fat was visible on the pins and if corrugations were visible at least halfway between the tip and spine of short ribs, the cow was assigned a BCS $\leq 2.25$. For operations with parlors, evaluators were trained to score cows when returning to their home pen from the parlor. Because time constraints were likely to limit the amount of information that could be collected while cows passed the evaluators, they were instructed to score cows for locomotion and body condition as they returned from the milking parlor to their home pens, and follow the cows back to the pen to assess hock lesions. Locomotion, hock, and body condition scores were not assigned to individual cows, so a cow-level relationship among the 3 scores could not be evaluated.

The specific instructions provided to the evaluators performing the lameness, hock, and body condition scoring were as follows: 
"The number of cows evaluated depends on herd size and we suggested approximately $1 \mathrm{~h}$ be allocated to the cow evaluation. If the operation has 100 cows or fewer, there is likely time to complete the evaluations on all cows within $1 \mathrm{~h}$. If the operation has more than 100 cows, we suggest picking a pen or maybe 2 pens at most to evaluate. The high production pen (cows 30 to $120 \mathrm{~d}$ in milk) is the highest priority for pen selection. It is not recommended to locomotion score cows while in their pen/stalls but rather as they are returning from the outside lot/pasture or from the milking parlor. The same cows should be evaluated for all 3 components. Low BCS cows can be identified at the same time as the lameness evaluation but the hock scoring might have to be done when the cows are in their pen or stalls."

\section{Statistical Analysis}

The overall survey design was a stratified random sample with unequal selection probabilities in each stratum. The unequal selection probabilities were implemented to ensure that large and organic operations were represented in the sample. Operation-level weights were provided by NASS and accounted for the selection criteria and study nonresponse. These weights were used to generate national estimates of the US dairy industry. All statistical analyses accounted for both the complex survey design and the individual farm weights. The operations participating in the cow evaluation component were a subset of the original sample and their initial selection weights were adjusted to represent the population from which they were selected.

Data from phase I were entered and validated by NASS staff using SAS (version 9.4; SAS Institute Inc., Cary, NC). Once the data had been compiled from all 17 states, the entire data set was validated again by NAHMS staff. Data from phase II were validated by state coordinators, and questionnaires were then sent to NAHMS. Data entry and additional validation were completed by NAHMS staff. The cow evaluation data were evaluated and entered into an Excel 2013 spreadsheet (Microsoft Corp., Redmond, WA) by NAHMS staff. Excel data were imported into SAS for further analysis. Descriptive data were analyzed using SAScallable SUDAAN (RTI International, Research Triangle Park, NC); SUDAAN was used because variance estimation accounted for the complex sampling design, including stratification by state and herd size, using the Taylor linearization method. Selection weights were adjusted for nonresponse within state/herd size strata. The SUDAAN procedures used included DE-
SCRIPT, CROSSTAB, RATIO, and LOGLINK. The DESCRIPT procedure produces means and totals for continuous data, and CROSSTAB produces weighted frequencies and percentage distributions for one-way and multi-way tabulations for categorical data. The RATIO procedure produces ratios and their standard errors, and LOGLINK fits count data by using a loglinear model.

Five log-linear models, using operation weights, were constructed to evaluate associations between housing and management practices and the following farm-level outcomes: number of cows that were lame (LS $\geq 2$ ), number of severely lame cows ( $\mathrm{LS}=3$ ), number of cows with any hock lesions (HS $\geq 2$ ), number of cows with severe hock lesions ( $\mathrm{HS}=3$ ), and number of thin cows $(\mathrm{BCS} \leq 2.25)$. All potential explanatory variables were screened individually for significance with the outcome variables using PROC LOGLINK in the SAS-callable SUDAAN program, with the natural logarithm of total cows scored as the offset term. Several steps were used to determine which explanatory variables would be included in the final models. Variables that were considered for inclusion in the analysis had plausible biological links with the outcome variables, as well as variables that had proven to be significantly linked with the outcome variables in previously reported research studies. Variables with $P<0.20$ were eligible for inclusion in the initial multivariable models. Variables that met the criteria for inclusion were evaluated for collinearity using the Pearson correlation matrix in PROC CORR of SAS. Correlation coefficients $\geq 0.70$ with $P<$ 0.0001 were evaluated and, if two variables were correlated by the criterion, one of the variables was chosen for inclusion in the initial multivariable model, using biological importance and model fit to choose between the two.

The group of cows scored (e.g., entire herd, high production pen), scoring surface (i.e., concrete or dirt/ other), and surface condition (i.e., dry, wet/snow/ice) were included as covariates, regardless of significance, in the multivariable lameness models. The group of cows scored was included as a covariate, again regardless of significance, in the multivariable hock and thin cow models. Stepwise backward elimination procedures were used in PROC LOGLINK to construct the final models, with Wald F $P<0.05$ indicating significance and inclusion in the final model. Model fit was evaluated using deviance tests by comparing the $-2 \times$ normalized log-likelihood values, with lower values suggesting a better fit to the data.

An incidence density ratio was calculated in SAS by exponentiating the estimated $\beta$-coefficient and was interpreted similarly to a risk ratio relative to the ref- 
erent level of the explanatory variable. The predicted marginal percentage was the model-predicted outcome for each level of the explanatory variable after adjusting for all other variables. The predicted marginal was interpreted similar to an estimated prevalence.

Confounding was evaluated by individually adding back each variable removed during the backward elimination procedure and comparing the crude and adjusted incidence density ratios. If the percentage change was greater than $15 \%$ and the change in the incidence density ratio was at least one unit, the variable was considered as a confounder.

\section{RESULTS}

Cow evaluations were completed on 191 operations by 76 different evaluators. A single evaluator made all the evaluations for an individual operation. Locomotion scoring was conducted on 184 operations and 22,042 cows were scored. Hocks were scored on 191 operations and 22,622 cows were assessed, and 190 operations and 22,458 cows were scored for BCS (Table 1). A total of $9.6 \%$ (95\% CI: 7.3 to 11.9$)$ of cows were classified as lame (LS $\geq 2$ ) and $2.7 \%$ (95\% CI: 1.6 to 3.9 ) as severely lame (Table 2). We detected no differences in the percentage of cows in each scoring category by herd size or region. Any hock lesions (HS $\geq 2$ ) were found in $12.7 \%$ of cows (95\% CI: 9.6 to 15.8 ), and $2.6 \%$ of cows $(95 \%$ CI: 1.7 to 3.4 ) had severe lesions. A higher percentage of cows on small operations had HS $=2(21.5 \%)$ or HS $=3(6.3 \%)$ compared with cows on medium-sized (7.6 and $1.7 \%$, respectively) and large operations (4.6 and $0.8 \%$, respectively). A small percentage of cows $(4.2 \%$; 95\% CI: 2.6 to 5.8 ) was determined to be thin (BCS $\leq 2.25)$. The highest percentage of thin cows (9.1\%) was found on small operations. Operations in the West region had a lower percentage of thin cows than those in the East (1.9 and 4.7\%, respectively).

The mean within-herd prevalence for mild/moderate lameness $(\mathrm{LS}=2)$ was $7.2 \%(\mathrm{SE}=0.7)$ and for severe lameness $(\mathrm{LS}=3$ ) was $2.6 \%(\mathrm{SE}=0.3$; Table 3$)$. The mean within-herd prevalence for mild hock lesions (HS $=2)$ was $13.6 \%(\mathrm{SE}=1.8)$ and that for severe hock lesions was $3.6 \%(\mathrm{SE}=0.6)$. The mean within-herd prevalence of cows with a BCS $\leq 2.25$ was $6.0 \%$ (SE $=1.5)$. Similar to the percentage of cows noted above, small operations had a higher within-herd prevalence of cows with hock lesions and thin cows.

Within-herd prevalence for lameness ( $\mathrm{LS} \geq 2$ ) ranged from $47.9 \%$ of cows being lame on one operation to many operations with no lame cows (Table 4). The range was also large for hock lesions; the maximum percentage of cows with mild/moderate hock lesions (LS $\geq 2$ ) was $66.1 \%$ and the maximum percentage of

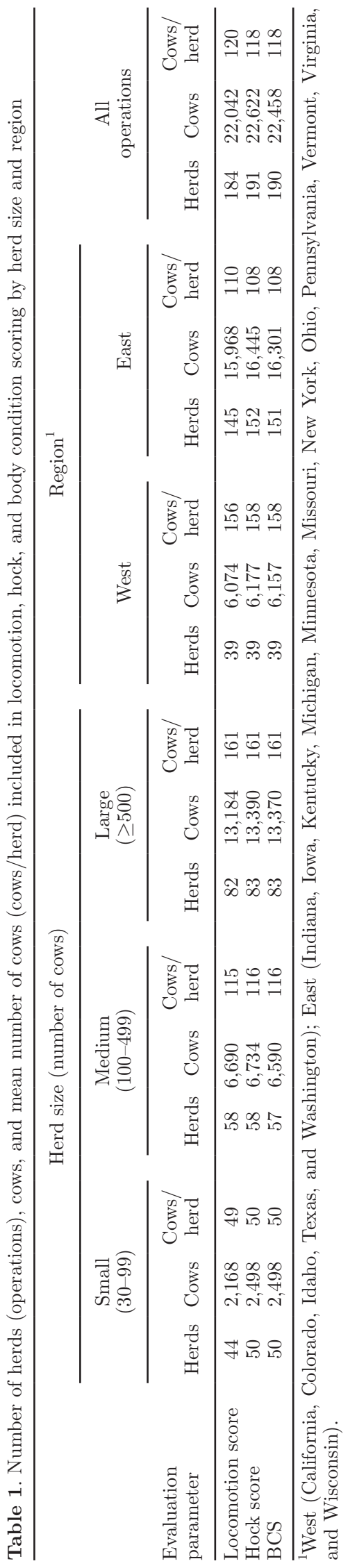


Table 2. Percentage of cows (SE in parentheses) by locomotion score, hock score, and low BCS by herd size and region

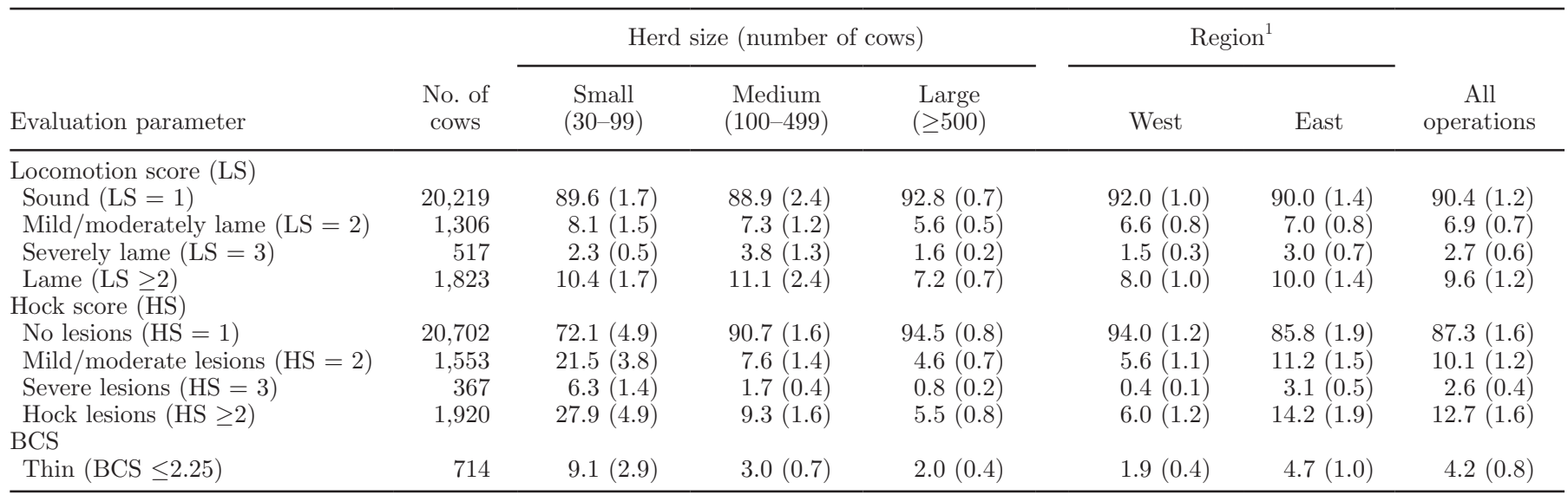

${ }^{1}$ West (California, Colorado, Idaho, Texas, and Washington); East (Indiana, Iowa, Kentucky, Michigan, Minnesota, Missouri, New York, Ohio, Pennsylvania, Vermont, Virginia, and Wisconsin).

Table 3. Operation average within-herd prevalence (\%, with SE in parentheses) of cows by locomotion score, hock score, and low BCS by herd size and region

\begin{tabular}{|c|c|c|c|c|c|c|}
\hline Evaluation parameter & \multicolumn{3}{|c|}{ Herd size (number of cows) } & \multicolumn{2}{|c|}{ Region $^{1}$} & $\begin{array}{c}\text { All } \\
\text { operations }\end{array}$ \\
\hline Sound $(\mathrm{LS}=1)$ & $90.0(1.5)$ & $89.5(1.5)$ & $92.2(0.7)$ & $92.3(1.1)$ & $89.9(1.0)$ & $90.2(0.9)$ \\
\hline Mild/moderately lame $(\mathrm{LS}=2)$ & $7.7(1.4)$ & $7.3(0.9)$ & $6.0(0.5)$ & $6.3(1.0)$ & $7.4(0.8)$ & $7.2(0.7)$ \\
\hline Severely lame $(\mathrm{LS}=3)$ & $2.3(0.5)$ & $3.3(0.7)$ & $1.9(0.3)$ & $1.4(0.3)$ & $2.7(0.4)$ & $2.6(0.3)$ \\
\hline No lesions $(\mathrm{HS}=1)$ & $73.5(4.6)$ & $89.9(1.7)$ & $93.6(1.1)$ & $93.2(1.8)$ & $81.4(2.6)$ & $82.8(2.3)$ \\
\hline Mild/moderate lesions $(\mathrm{HS}=2)$ & $20.7(3.5)$ & $8.3(1.4)$ & $5.3(1.0)$ & $6.4(1.7)$ & $14.6(2.1)$ & $13.6(1.8)$ \\
\hline Severe lesions $(\mathrm{HS}=3)$ & $5.8(1.3)$ & $1.8(0.4)$ & $1.1(0.2)$ & $0.5(0.2)$ & $4.0(0.7)$ & $3.6(0.6)$ \\
\hline Hock lesions (HS >2) & $26.5(4.6)$ & $10.1(1.7)$ & $6.4(1.1)$ & $6.8(1.8)$ & $18.6(2.6)$ & $17.2(2.3)$ \\
\hline \multicolumn{7}{|l|}{ BCS } \\
\hline Thin $(\mathrm{BCS}<2.25)$ & $9.7(3.0)$ & $2.8(0.6)$ & $2.3(0.4)$ & $1.8(0.4)$ & $6.5(1.7)$ & $6.0(1.5)$ \\
\hline
\end{tabular}

${ }^{1}$ West (California, Colorado, Idaho, Texas, and Washington); East (Indiana, Iowa, Kentucky, Michigan, Minnesota, Missouri, New York, Ohio, Pennsylvania, Vermont, Virginia, and Wisconsin).

Table 4. Distribution of within-herd prevalence of lameness, hock lesions, and thin cows

\begin{tabular}{|c|c|c|c|c|c|c|c|}
\hline Evaluation parameter & $\underset{(\%)}{\operatorname{Minimum}}$ & \multicolumn{5}{|c|}{ Percentile $[\%(\mathrm{SE})]$} & $\underset{(\%)}{\operatorname{Maximum}}$ \\
\hline Sound $(\mathrm{LS}=1)$ & 52.1 & $78.2(2.3)$ & $86.2(1.9)$ & $90.2(0.9)$ & $96.4(0.5)$ & $98.9(0.4)$ & 100.0 \\
\hline Mild/moderately lame $(\mathrm{LS}=2)$ & 0.0 & $0.0(-)$ & $2.3(0.5)$ & $7.2(0.7)$ & $9.5(1.0)$ & $16.6(2.9)$ & 25.5 \\
\hline Severely lame $(\mathrm{LS}=3)$ & 0.0 & $0.0(-)$ & $0.0(-)$ & $2.6(0.3)$ & $3.8(0.6)$ & $7.1(1.1)$ & 25.0 \\
\hline Lame (LS $\geq 2)$ & 0.0 & $1.0(0.4)$ & $3.4(0.5)$ & $9.8(0.9)$ & $13.6(1.8)$ & $21.1(2.4)$ & 47.9 \\
\hline Mild/moderate lesions $(\mathrm{HS}=2)$ & 0.0 & $0.0(-)$ & $1.0(0.4)$ & $13.6(1.8)$ & $17.1(4.2)$ & $45.4(8.8)$ & 66.1 \\
\hline Severe lesions $(\mathrm{HS}=3)$ & 0.0 & $0.0(-)$ & $0.0(-)$ & $3.6(0.6)$ & $4.1(1.5)$ & $11.7(3.6)$ & 35.6 \\
\hline Hock lesions (HS $\geq 2$ ) & 0.0 & $0.0(-)$ & $1.7(0.4)$ & $17.2(2.3)$ & $21.1(5.1)$ & $56.6(9.7)$ & 91.1 \\
\hline \multicolumn{8}{|l|}{$\mathrm{BCS}$} \\
\hline Thin $(\mathrm{BCS} \leq 2.25)$ & 0.0 & $0.0(-)$ & $0.0(-)$ & $6.0(1.5)$ & $4.2(1.5)$ & $16.2(10.0)$ & 62.9 \\
\hline
\end{tabular}


cows with severe lesions ( $\mathrm{LS}=3$ ) was $35.6 \%$. More than $90 \%$ of operations had less than $20 \%$ of their cows with $\mathrm{BCS} \leq 2.25$ but the maximum percentage of thin cows on an operation was $62.9 \%$.

\section{Lameness Models}

Of the 12 variables considered for inclusion in the multivariable lameness model (Table 5), 6 met the

Table 5. Categorical variables used in the univariate analysis of variables associated with lameness, severe lameness, hock lesions, severe hock lesions, and thin cows on US dairy operations ${ }^{1}$

\begin{tabular}{|c|c|c|c|c|c|c|c|}
\hline \multirow[b]{2}{*}{ Categorical variable } & \multirow[b]{2}{*}{ Level } & \multirow[b]{2}{*}{$\begin{array}{l}\text { Herds } \\
(\%)\end{array}$} & \multicolumn{5}{|c|}{$P$-value } \\
\hline & & & Lame $^{2}$ & $\begin{array}{l}\text { Severely } \\
\text { lame }^{2}\end{array}$ & $\begin{array}{c}\text { Any } \\
\text { hock } \\
\text { lesions }\end{array}$ & $\begin{array}{c}\text { Severe } \\
\text { hock } \\
\text { lesions }\end{array}$ & $\begin{array}{l}\text { Thin } \\
\text { cows }^{4}\end{array}$ \\
\hline \multirow[t]{3}{*}{ Group of cows scored } & High production pen & 35.8 & $\mathrm{NA}^{5}$ & NA & NA & NA & NA \\
\hline & Medium/low production pens & 16.3 & & & & & \\
\hline & Whole herd & 47.9 & & & & & \\
\hline \multirow[t]{2}{*}{ Scoring surface } & Concrete & 85.0 & NA & NA & NA & NA & NA \\
\hline & Dirt/other & 15.0 & & & & & \\
\hline \multirow[t]{2}{*}{ Surface conditions } & Dry & 36.1 & NA & NA & NA & NA & NA \\
\hline & Wet/snow/ice & 63.9 & & & & & \\
\hline \multirow[t]{3}{*}{ Herd size } & Small (30-99) & 26.2 & 0.002 & $<0.001$ & $<0.001$ & $<0.001$ & 0.015 \\
\hline & Medium (100-499) & 30.4 & & & & & \\
\hline & Large $(\geq 500)$ & 43.4 & & & & & \\
\hline \multirow[t]{2}{*}{ Region $^{6}$} & West & 20.4 & 0.967 & 0.048 & 0.041 & $<0.001$ & 0.261 \\
\hline & East & 79.6 & & & & & \\
\hline \multirow[t]{3}{*}{ Operation type } & Conventional (C) & 78.7 & 0.609 & 0.286 & 0.002 & 0.078 & 0.443 \\
\hline & Grazing (G)/Combination C-G & 14.9 & & & & & \\
\hline & Organic & 6.4 & & & & & \\
\hline \multirow[t]{4}{*}{ Primary housing type } & Tiestall/stanchion & 16.4 & 0.190 & 0.096 & $<0.001$ & $<0.001$ & 0.216 \\
\hline & Pasture & 5.3 & & & & & \\
\hline & Freestall & 68.3 & & & & & \\
\hline & Open lot & 10.0 & & & & & \\
\hline \multirow[t]{6}{*}{ Primary bedding material } & Straw/hay/corn stalks & 20.4 & 0.003 & 0.151 & $<0.001$ & $<0.001$ & NA \\
\hline & Sawdust/wood products & 17.8 & & & & & \\
\hline & Dried or composted manure & 14.7 & & & & & \\
\hline & Rubber mats/mattresses & 8.4 & & & & & \\
\hline & Other & 5.2 & & & & & \\
\hline & Sand & 33.5 & & & & & \\
\hline \multirow{4}{*}{$\begin{array}{l}\text { Outside area for lactating } \\
\text { cows in summer }\end{array}$} & Pasture & 29.3 & 0.659 & 0.160 & 0.131 & 0.146 & NA \\
\hline & Concrete & 10.6 & & & & & \\
\hline & Open/dry lot & 23.4 & & & & & \\
\hline & None & 36.7 & & & & & \\
\hline \multirow{4}{*}{$\begin{array}{l}\text { Outside area for lactating } \\
\text { cows in winter }\end{array}$} & Pasture & 5.3 & 0.058 & 0.098 & 0.017 & 0.003 & NA \\
\hline & Concrete & 14.7 & & & & & \\
\hline & Open/dry lot & 30.5 & & & & & \\
\hline & None & 49.5 & & & & & \\
\hline \multirow{4}{*}{$\begin{array}{l}\text { Outside area for dry cows } \\
\text { in summer }\end{array}$} & Pasture & 36.3 & 0.241 & 0.016 & 0.248 & 0.442 & NA \\
\hline & Concrete & 10.0 & & & & & \\
\hline & Open/dry lot & 27.9 & & & & & \\
\hline & None & 25.8 & & & & & \\
\hline \multirow{4}{*}{$\begin{array}{l}\text { Outside area for dry cows } \\
\text { in winter }\end{array}$} & Pasture & 10.0 & 0.041 & 0.541 & $<0.001$ & $<0.001$ & NA \\
\hline & Concrete & 11.1 & & & & & \\
\hline & Open/dry lot & 42.9 & & & & & \\
\hline & None & 36.0 & & & & & \\
\hline \multirow[t]{3}{*}{ Flooring type } & Concrete & 74.1 & 0.286 & 0.394 & $<0.001$ & $<0.001$ & NA \\
\hline & Rubber mats on concrete & 11.1 & & & & & \\
\hline & Pasture/dirt & 14.8 & & & & & \\
\hline \multirow{2}{*}{$\begin{array}{l}\text { Rubber mats adjacent } \\
\text { to feedbunk }\end{array}$} & Yes & 15.3 & 0.087 & 0.844 & NA & NA & 0.262 \\
\hline & No/NA & 84.7 & & & & & \\
\hline Rubber mats in freestall & Yes & 8.9 & 0.808 & 0.001 & NA & NA & NA \\
\hline alleyway & $\mathrm{No} / \mathrm{NA}$ & 91.1 & & & & & \\
\hline Rubber mats in walkway & Yes & 15.3 & 0.078 & 0.017 & NA & NA & NA \\
\hline to parlor & $\mathrm{No} / \mathrm{NA}$ & 84.7 & & & & & \\
\hline Rubber mats in holding & Yes & 17.9 & 0.273 & 0.909 & NA & NA & NA \\
\hline pen & $\mathrm{No} / \mathrm{NA}$ & 82.1 & & & & & \\
\hline
\end{tabular}


Table 5 (Continued). Categorical variables used in the univariate analysis of variables associated with lameness, severe lameness, hock lesions, severe hock lesions, and thin cows on US dairy operations ${ }^{1}$

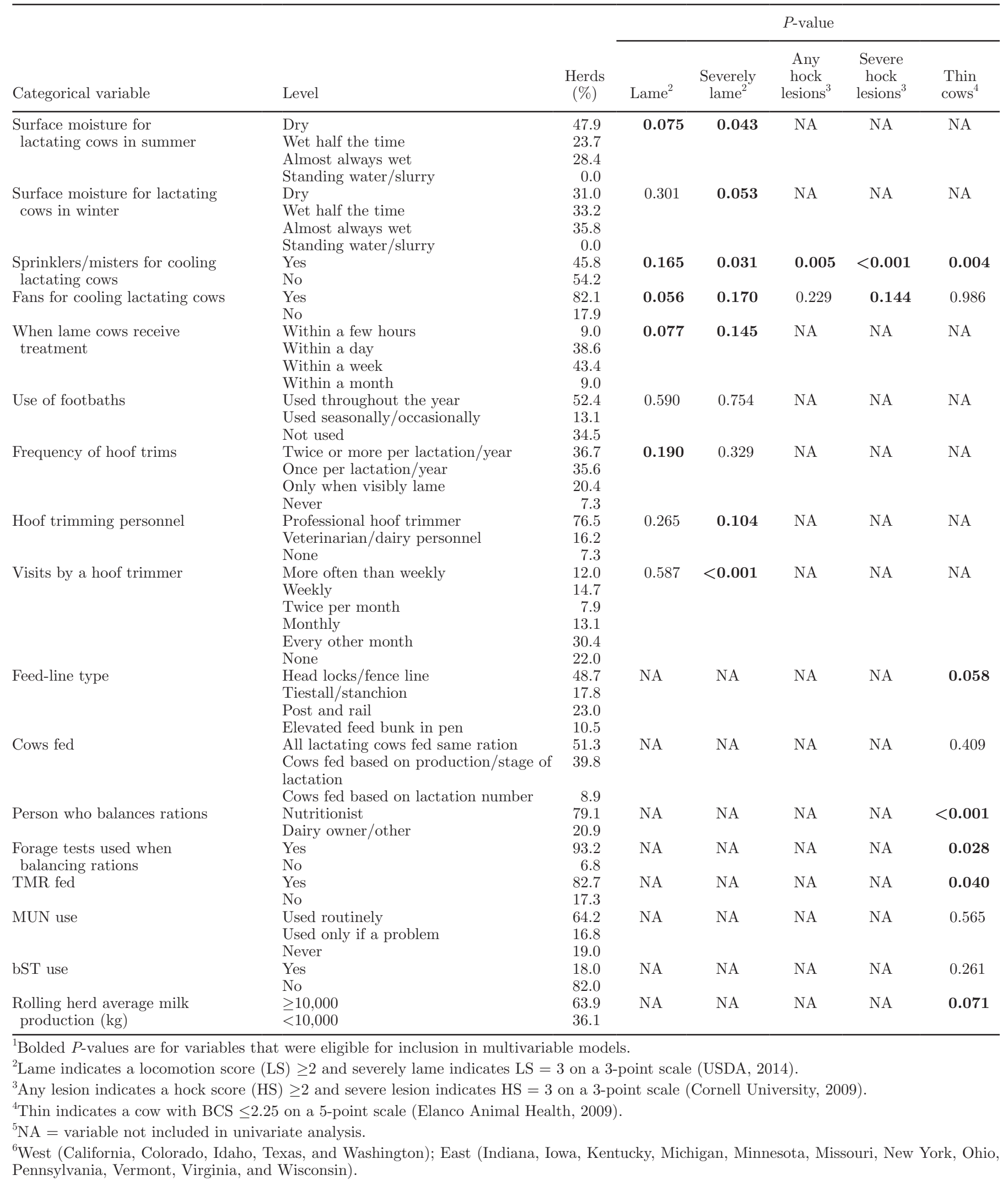


criteria for inclusion in the final model, being associated with lameness after controlling for the covariates (Table 6). Additional variables that were considered for inclusion but did not meet the criteria included housing type, footbath use, outside area for lactating cows during the summer, and rubber mats in the holding pen or freestall alleyways. The size of the operation was associated with cow lameness, with small and medium-sized dairies having more lame cows than large operations $(P<0.001)$. Lameness was associated with bedding material, with operations using sand as the primary bedding having a lower prevalence of lameness than those using straw/hay/corn stalks $(P=0.033)$, dried or composted manure $(P=0.036)$, or "other" (usually a combination) bedding types $(P=0.009)$. No differences in lameness were found between operations using sand, sawdust/wood products, and rubber mats/mattresses as the primary bedding material. The surface moisture of the outside area that cows had access to during the summer was shown to have an effect, with operations on which the surface was wet half the time having a lower prevalence of lameness than those on which the surface was dry $(P=0.016)$ or almost always wet $(P=0.023)$. Operations that used fans to provide cooling for cows had an increased prevalence of lameness compared with operations that did not use fans $(P<0.001)$. The amount of time before cows received treatment after being identified as lame was associated with lameness $(P<0.001)$, with the model-predicted prevalence of lameness being lower on operations on which cows received treatment within a day or week compared with operations on which lame cows received treatment within a few hours or within a month. The frequency of hoof trimming was also associated with lameness $(P<0.030)$. Operations on which hoof trimming was performed only when cows were visibly lame had a lower lameness prevalence than operations that trimmed hooves at least once per lactation.

Of the 16 variables that met univariate screening criteria for severe lameness, 6 were found to be associated with severe lameness after controlling for covariates (Table 7). Additional variables that were considered for inclusion but did not meet the criteria included footbath use, frequency of hoof trims, flooring type, and rubber mats adjacent to the feedbunk or in the holding pen. The size of the operation was associated with severe lameness in cows $(P=0.006)$, with small and medium-sized operations having a higher prevalence of severely lame cows than large operations. Housing type was shown to have an effect on the percentage of cows that were severely lame, with operations that housed cows on pasture having a lower prevalence of severely lame cows than operations that housed them in freestall barns $(P=0.002)$ or open/dry lots $(P=0.030)$. Operations that used sand bedding had a lower prevalence of severely lame cows than those that used all other bedding types except rubber mats/mattresses. Operations on which cows had outside access to concrete had a higher prevalence of severe lameness than operations on which cows had access to open/dry lots $(P=0.002)$ or no outside access $(P=0.004)$. The use of sprinklers/ misters for cooling was associated with a lower prevalence of severe lameness $(P=0.004)$. Monthly visits by a hoof trimmer were associated with a lower prevalence of severe lameness compared with weekly visits $(P=$ $0.013)$ or no hoof trimmer visits $(P=0.024)$.

\section{Hock Lesion Models}

Ten variables were introduced into a multivariable model for the prevalence of any hock lesions, with 4 being included in the final multivariable model after controlling for group of cows scored (Table 8). The type of operation had an effect on the prevalence of hock lesions $(P<0.001)$, with organic operations having a lower prevalence of hock lesions than conventional operations. Housing type was associated with the prevalence of hock lesions $(P<0.001)$, with cows housed in an open/dry lot having a lower prevalence of hock lesions than those housed in freestalls, tiestall/ stanchions, or on pasture. A relationship was found between hock lesions and bedding material, with sand bedding being associated with a lower prevalence of hock lesions than straw/hay/corn stalks $(P<0.001)$, sawdust/wood products $(P<0.001)$, dry/composted manure $(P=0.002)$, and rubber mats $/$ mattresses $(P<$ $0.001)$. Finally, the outside area that dry cows had access to during the winter had an effect, with operations housing dry cows on pasture having a lower prevalence of hock lesions than those housing dry cows in open/ dry lots $(P<0.001)$ or that did not provide dry cows with outside access $(P<0.001)$.

After controlling for the scoring group, 4 of the 11 variables considered for inclusion in the multivariable model for severe hock lesions were retained in the final model (Table 9). Housing type was also significantly associated with the prevalence of severe hock lesions $(P$ $=0.003$ ). As observed in the first hock lesion model (for the presence of any hock lesion), open/dry lots were associated with a lower prevalence of severe hock lesions compared with other housing types. Bedding material was significantly associated with the prevalence of severe hock lesions $(P<0.001)$. Operations using sand as their primary bedding had a lower prevalence of severe hock lesions than those using straw/hay/corn stalks $(P$ $<0.001)$ or sawdust/wood products $(P=0.007)$. The 
Table 6. Explanatory factors included in the multivariable analysis for association with dairy cows being lame (locomotion score $\geq 2$ ) on US dairy operations $(\mathrm{n}=173)$

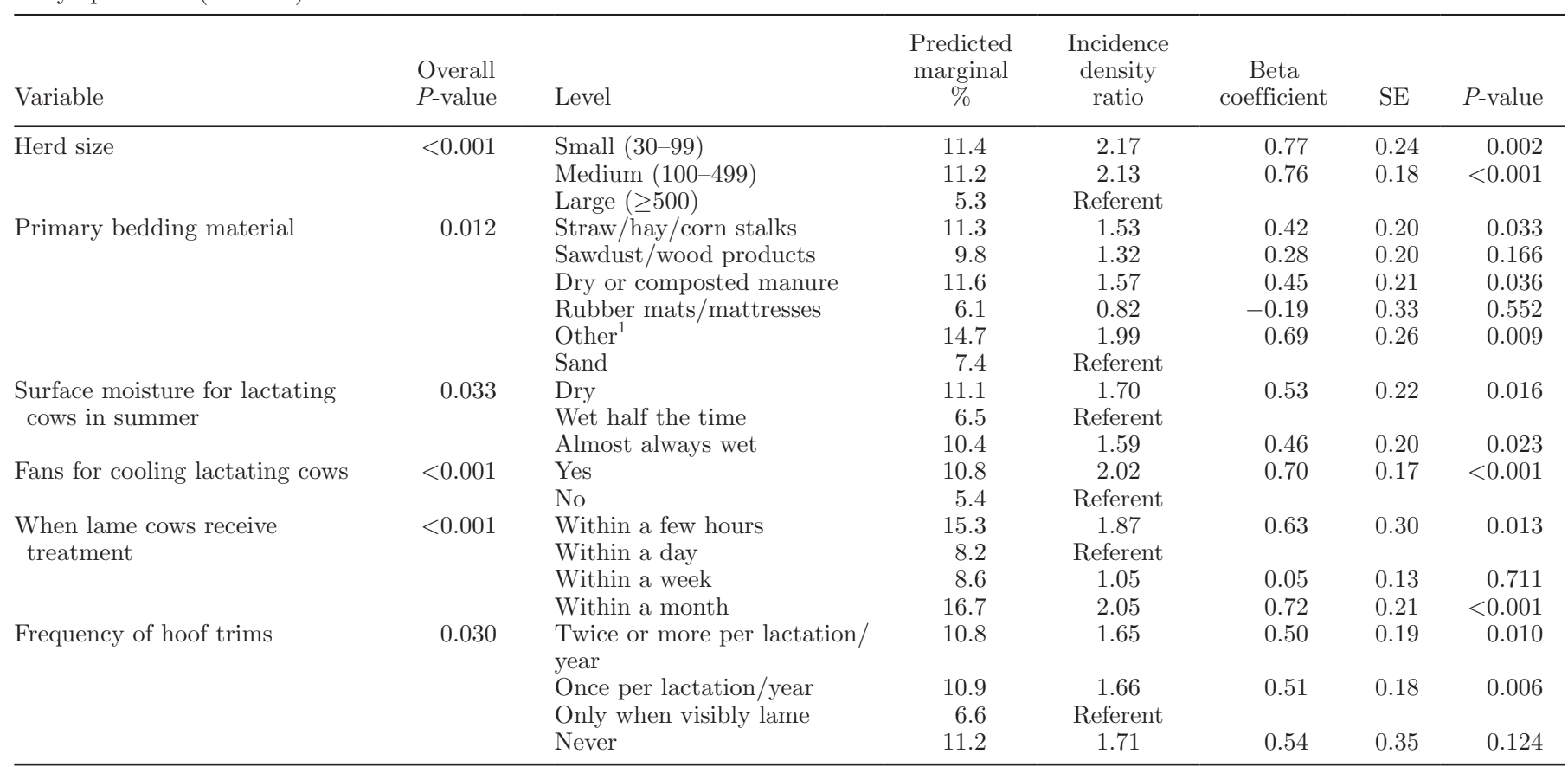

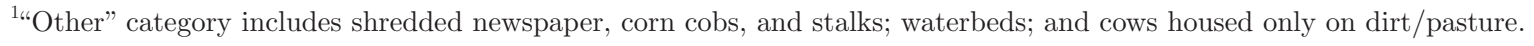

Table 7. Explanatory factors included in the multivariable analysis for association with dairy cows being severely lame (locomotion score $=3$ ) on US dairy operations $(\mathrm{n}=174)$

\begin{tabular}{|c|c|c|c|c|c|c|c|}
\hline Variable & $\begin{array}{l}\text { Overall } \\
P \text {-value }\end{array}$ & Level & $\begin{array}{c}\text { Predicted } \\
\text { marginal } \\
\%\end{array}$ & $\begin{array}{c}\text { Incidence } \\
\text { density } \\
\text { ratio }\end{array}$ & $\begin{array}{c}\text { Beta } \\
\text { coefficient }\end{array}$ & $\mathrm{SE}$ & $P$-value \\
\hline \multirow[t]{2}{*}{ Herd size } & \multirow{2}{*}{0.006} & Small (30-99) & 3.3 & 3.56 & 1.27 & 0.60 & 0.037 \\
\hline & & Large $(\geq 500)$ & 0.9 & Referent & & & \\
\hline \multirow[t]{2}{*}{ Primary housing type } & \multirow[t]{2}{*}{0.003} & Tiestall/stanchion & 1.5 & 3.23 & 1.17 & 0.81 & 0.149 \\
\hline & & Freestall & 3.2 & 6.92 & 1.93 & 0.60 & 0.002 \\
\hline \multirow{5}{*}{ Primary bedding material } & \multirow{5}{*}{0.010} & Sawdust/wood products & 3.1 & 2.08 & 0.73 & 0.36 & 0.045 \\
\hline & & Dry or composted manure & 3.5 & 2.33 & 0.85 & 0.28 & 0.003 \\
\hline & & Rubber mats/mattresses & 1.6 & 1.07 & 0.06 & 0.59 & 0.915 \\
\hline & & Other ${ }^{1}$ & 4.7 & 3.14 & 1.14 & 0.38 & 0.003 \\
\hline & & Sand & 1.5 & Referent & & & \\
\hline $\begin{array}{l}\text { Outside area for lactating } \\
\text { cows in winter }\end{array}$ & 0.007 & Pasture & 3.0 & 0.60 & -0.41 & 0.60 & 0.398 \\
\hline \multirow{6}{*}{ Visits by a hoof trimmer } & \multirow[t]{6}{*}{0.005} & More often than weekly & 1.8 & 1.23 & 0.21 & 0.50 & 0.681 \\
\hline & & Weekly & 4.8 & 3.19 & 1.16 & 0.46 & 0.013 \\
\hline & & Twice per month & 2.6 & 1.75 & 0.56 & 0.49 & 0.254 \\
\hline & & Monthly & 1.5 & Referent & & & \\
\hline & & Every other month & 2.0 & 1.32 & 0.27 & 0.44 & 0.538 \\
\hline & & None & 4.4 & 2.95 & 1.08 & 0.48 & 0.024 \\
\hline
\end{tabular}

\footnotetext{
${ }^{1 " O t h e r " ~ c a t e g o r y ~ i n c l u d e s ~ s h r e d d e d ~ n e w s p a p e r, ~ c o r n ~ c o b s, ~ a n d ~ s t a l k s ; ~ w a t e r b e d s ; ~ a n d ~ c o w s ~ h o u s e d ~ o n l y ~ o n ~ d i r t / p a s t u r e . ~}$
} 
Table 8. Explanatory factors included in the multivariable analysis for association with dairy cows having hock lesions (hock score $\geq 2$ ) on US dairy operations $(\mathrm{n}=185)$

\begin{tabular}{|c|c|c|c|c|c|c|c|}
\hline Variable & $\begin{array}{l}\text { Overall } \\
P \text {-value }\end{array}$ & Level & $\begin{array}{c}\text { Predicted } \\
\text { marginal } \\
\%\end{array}$ & $\begin{array}{c}\text { Incidence } \\
\text { density } \\
\text { ratio }\end{array}$ & $\begin{array}{c}\text { Beta } \\
\text { coefficient }\end{array}$ & $\mathrm{SE}$ & $P$-value \\
\hline \multirow[t]{3}{*}{ Operation type } & \multirow[t]{3}{*}{$<0.001$} & Conventional (C) & 22.6 & 3.14 & 1.14 & 0.27 & $<0.001$ \\
\hline & & Grazing (G)/Combination C-G & 11.6 & 1.61 & 0.48 & 0.34 & 0.158 \\
\hline & & Organic & 7.2 & Referent & & & \\
\hline \multirow[t]{4}{*}{ Primary housing type } & \multirow[t]{4}{*}{$<0.001$} & Tie-stall/stanchion & 20.7 & 5.00 & 1.61 & 0.38 & $<0.001$ \\
\hline & & Pasture & 40.3 & 9.72 & 2.27 & 0.40 & $<0.001$ \\
\hline & & Freestall & 13.7 & 3.29 & 1.19 & 0.33 & $<0.001$ \\
\hline & & Open/dry lot & 4.1 & Referent & & & \\
\hline \multirow{6}{*}{ Primary bedding material } & \multirow[t]{6}{*}{$<0.001$} & Straw/hay/corn stalks & 30.5 & 9.25 & 2.22 & 0.43 & $<0.001$ \\
\hline & & Sawdust/wood products & 16.5 & 5.00 & 1.61 & 0.45 & $<0.001$ \\
\hline & & Dry or composted manure & 11.4 & 3.44 & 1.23 & 0.40 & 0.002 \\
\hline & & Rubber mats/mattresses & 15.8 & 4.80 & 1.57 & 0.46 & $<0.001$ \\
\hline & & Other ${ }^{1}$ & 2.6 & 0.79 & -0.23 & 0.44 & 0.593 \\
\hline & & Sand & 3.3 & Referent & & & \\
\hline \multirow{4}{*}{$\begin{array}{l}\text { Outside area for dry cows } \\
\text { in the winter }\end{array}$} & \multirow[t]{4}{*}{0.003} & Concrete & 12.0 & 2.27 & 0.82 & 0.51 & 0.110 \\
\hline & & Open/dry lot & 18.0 & 3.40 & 1.22 & 0.34 & $<0.001$ \\
\hline & & None & 20.0 & 3.77 & 1.33 & 0.36 & $<0.001$ \\
\hline & & Pasture & 5.3 & Referent & & & \\
\hline
\end{tabular}

"Other" category includes shredded newspaper, corn cobs, and stalks; waterbeds; and cows housed only on dirt/pasture.

outside area for dry cows during the winter affected the prevalence of severe hock lesions $(P=0.022)$. Operations on which dry cows had access to pasture during the winter had a lower prevalence of severe hock lesions compared with operations on which dry cows had access to an open/dry lot $(P=0.005)$ or no outside access $(P=0.004)$. Operations that used concrete flooring had a lower prevalence of severe hock lesions compared with operations that used rubber mats on concrete $(P$ $<0.001)$ or pasture/dirt $(P=0.035)$ as the predominant flooring type.

\section{Thin Cow Models}

Seven variables met the univariate screening criteria for the prevalence of thin cows, of which 2 were included in the final multivariable model after controlling for scoring group (Table 10). Additional variables that were considered for inclusion but did not meet the criteria included region, housing type, how lactating cows were fed (e.g., based on production level), and MUN testing. Operations that provided sprinklers/misters for cooling had a lower prevalence of thin cows than operations

Table 9. Explanatory factors included in the multivariable analysis for association with dairy cows having severe hock lesions $($ hock score $=3)$ on US dairy operations $(\mathrm{n}=185)$

\begin{tabular}{|c|c|c|c|c|c|c|c|}
\hline Variable & $\begin{array}{l}\text { Overall } \\
P \text {-value }\end{array}$ & Level & $\begin{array}{c}\text { Predicted } \\
\text { marginal } \\
\%\end{array}$ & $\begin{array}{c}\text { Incidence } \\
\text { density } \\
\text { ratio }\end{array}$ & $\begin{array}{c}\text { Beta } \\
\text { coefficient }\end{array}$ & $\mathrm{SE}$ & $P$-value \\
\hline \multirow[t]{4}{*}{ Primary housing type } & \multirow[t]{4}{*}{0.003} & Tie-stall/stanchion & 4.2 & 33.00 & 3.50 & 0.93 & $<0.001$ \\
\hline & & Pasture & 4.5 & 35.38 & 3.57 & 0.95 & $<0.001$ \\
\hline & & Freestall & 3.6 & 28.71 & 3.36 & 0.93 & $<0.001$ \\
\hline & & Open/dry lot & 0.1 & Referent & & & \\
\hline \multirow[t]{6}{*}{ Primary bedding material } & \multirow[t]{6}{*}{$<0.001$} & Straw/hay/corn stalks & 6.0 & 6.37 & 1.85 & 0.47 & $<0.001$ \\
\hline & & Sawdust/wood products & 3.6 & 3.83 & 1.34 & 0.49 & 0.007 \\
\hline & & Dry or composted manure & 0.4 & 0.46 & -0.77 & 0.53 & 0.151 \\
\hline & & Rubber mats/mattresses & 1.7 & 1.78 & 0.58 & 0.64 & 0.367 \\
\hline & & Other $^{1}$ & 0.5 & 0.56 & -0.57 & 0.60 & 0.343 \\
\hline & & Sand & 0.9 & Referent & & & \\
\hline \multirow{4}{*}{$\begin{array}{l}\text { Outside area for dry cows } \\
\text { in the winter }\end{array}$} & \multirow[t]{4}{*}{0.022} & Concrete & 2.2 & 5.44 & 1.69 & 0.88 & 0.055 \\
\hline & & Open/dry lot & 3.8 & 9.40 & 2.24 & 0.78 & 0.005 \\
\hline & & None & 4.1 & 10.21 & 2.32 & 0.80 & 0.004 \\
\hline & & Pasture & 0.4 & Referent & & & \\
\hline \multirow[t]{3}{*}{ Flooring type } & \multirow[t]{3}{*}{0.001} & Rubber mats on concrete & 5.8 & 2.87 & 1.05 & 0.30 & $<0.001$ \\
\hline & & Pasture/dirt & 5.3 & 2.60 & 0.96 & 0.45 & 0.035 \\
\hline & & Concrete & 2.0 & Referent & & & \\
\hline
\end{tabular}

"Other" category includes shredded newspaper, corn cobs, and stalks; waterbeds; and cows housed only on dirt/pasture. 
Table 10. Explanatory factors included in the multivariable analysis for association with thin dairy cows (BCS $\leq 2.25)$ on US dairy operations $(\mathrm{n}=188)$

\begin{tabular}{|c|c|c|c|c|c|c|c|}
\hline Variable & $\begin{array}{l}\text { Overall } \\
P \text {-value }\end{array}$ & Level & $\begin{array}{c}\text { Predicted } \\
\text { marginal } \\
\%\end{array}$ & $\begin{array}{c}\text { Incidence } \\
\text { density } \\
\text { ratio }\end{array}$ & Beta coefficient & $\mathrm{SE}$ & $P$-value \\
\hline Sprinklers/misters for cooling & 0.023 & $\begin{array}{l}\text { Yes } \\
\text { No }\end{array}$ & $\begin{array}{l}2.7 \\
6.3\end{array}$ & $\begin{array}{c}\text { Referent } \\
2.33\end{array}$ & 0.85 & 0.37 & 0.023 \\
\hline Person who balances rations & $<0.001$ & $\begin{array}{l}\text { Dairy owner/other } \\
\text { Nutritionist }\end{array}$ & $\begin{array}{r}11.8 \\
3.1\end{array}$ & $\begin{array}{c}3.81 \\
\text { Referent }\end{array}$ & 1.34 & 0.32 & $<0.001$ \\
\hline
\end{tabular}

that did not provide them $(P=0.023)$. Additionally, the person who was in charge of balancing the ration fed to lactating cows had an effect on the prevalence of thin cows, with operations that used a nutritionist to balance rations having a lower prevalence of thin cows than those on which the owner or other personnel $(P<$ 0.001 ) balanced rations.

General characteristics of the operation, including herd size, operation type, and housing type, were all associated with the prevalence of lameness and hock lesions (Table 11). Although the same variables were not present in both lameness models nor in both hock lesions models, the general categories of questions were similar. Variables related to bedding type and flooring were significant in both lameness and hock models. Systems designed to cool cows were important for prevalence of lameness and thin cows but were not associated with hock scores.

\section{DISCUSSION}

The prevalence of lame and severely lame cows in the current study was lower than many prevalence estimates previously reported. The mean within-herd prevalence of lameness in Wisconsin dairy herds during the summer was found to be $21.1 \%$ (Cook, 2003), which is similar to the prevalence of $21 \%$ found in a Canadian study (Solano et al., 2015), but is more than double that was found in the current study (9.8\%). Espejo et al. (2006) found the mean prevalence of lameness to be $24.6 \%$ for high-producing dairy cows in Minnesota, which again was much higher than that found in the current study. A study investigating lameness in dairy herds reported a mean lameness prevalence of $30 \%$ in California and British Columbia, and $55 \%$ in the northeastern United States (von Keyserlingk et al., 2012). That same study reported fewer cases of severe lameness, with the mean prevalence being $4 \%$ in California and $8 \%$ in British Columbia and the northeastern United States. All of these prevalence estimates are substantially higher than those reported in the current study. A study of high-performance herds in Wisconsin by Cook et al. (2016) found a lower prevalence of lameness using the 5 -point system. Overall, lameness was $13.2 \%$ and severe lameness was $2.5 \%$, which is similar to the results of this study. Similar results were found on dairy farms

Table 11. Summary of explanatory variables included in the 5 multivariable models for lameness, hock lesions, and thin cows (BCS $\leq 2.25)$ on US dairy operations

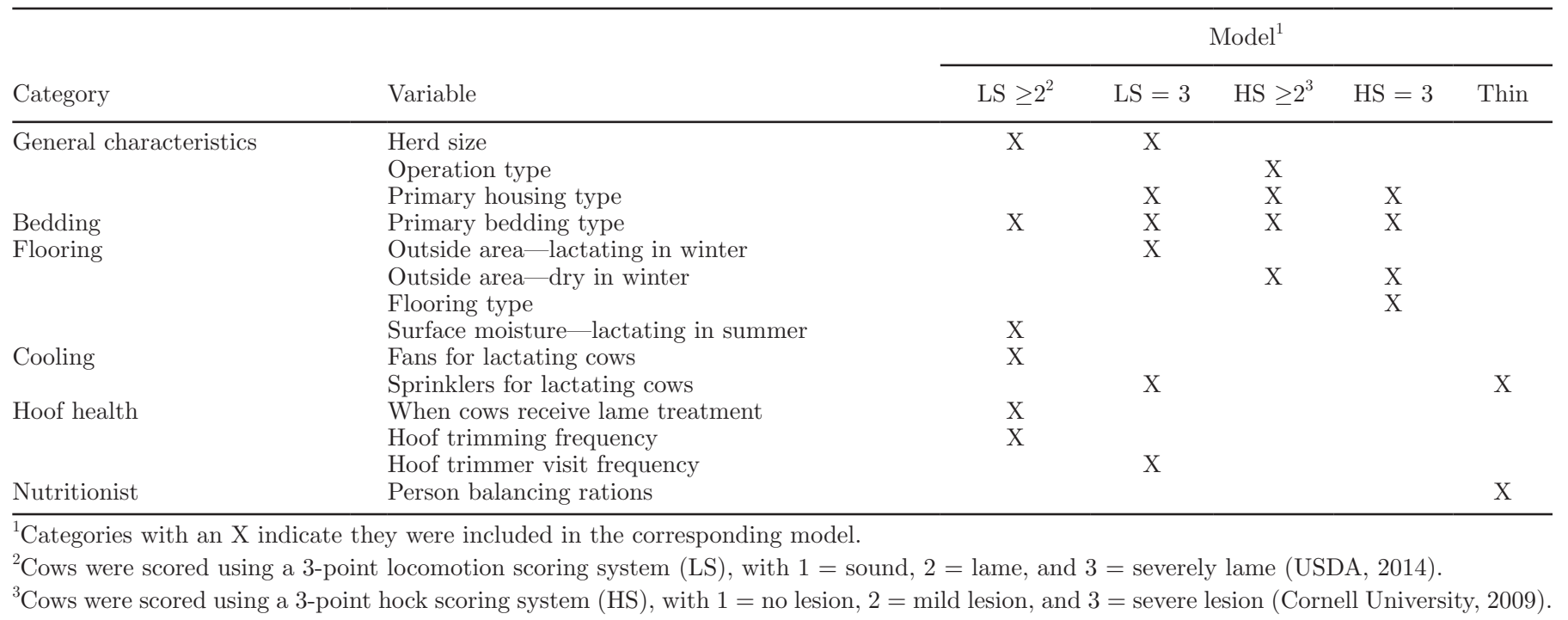


in Canada and Michigan (Westin et al., 2016), with an overall prevalence of lameness of $15 \%$, of which $4 \%$ were considered severely lame.

Lameness is considered one of the leading welfare problems facing the US dairy industry (O'Callaghan et al., 2003; Rushen et al., 2007), with different dairy characteristics and management practices contributing to the prevalence of lameness. Operation size was included in the models for predicting the prevalence of lame cows. Large operations had a lower percentage of lame and severely lame cows than small and medium-sized operations. The findings in the current study agree with 2 studies by Chapinal et al. (2013, 2014), who found that herd size was negatively associated with lameness on operations in New England, California, and in China. Those authors credited this association with the ability of large operations to have greater availability of dairy personnel to manage cow lameness and hoof health. Housing type was associated with the prevalence of severely lame cows on US dairy operations. We observed an increase in the prevalence of severely lame cows on operations that housed cows in freestall barns or in open lots compared with pasture, suggesting that benefits to hoof health and cow lameness exist in pasture-based systems that are not realized in other housing types. These findings have been illustrated in other studies as well; the prevalence of lameness was lower on freestall operations that allowed cows access to pasture than on operations on which cows were kept in freestalls year round (Haskell et al., 2006). Bedding material was associated with the prevalence of lameness; operations using organic materials such as straw/hay, sawdust, or dried/composted manure had an increased prevalence of lameness compared with operations that used sand or rubber mats/ mattresses for bedding. Similar results were found in herds in the northeastern United States, with sawdust bedding being associated with an increase in cow lameness (Chapinal et al., 2013). Surprisingly, no difference was found between the prevalence of lameness between operations using sand and those using rubber mats/ mattresses, which contradicts previous findings. In a study investigating cow lameness on farms in Wisconsin, the prevalence of lameness was significantly lower for herds with sand bedding compared with herds using mattress stalls (Cook, 2013). The different results from the 2 studies may be due to the Wisconsin study involving primarily freestall operations, whereas the current study included a wider range of housing types. In this study, some producers chose mattresses or rubber mats as their primary bedding type even though these are commonly considered stall bases. Because producers selected their primary bedding type, it is possible they either did not provide a typical bedding material or did not use a common bedding material enough to consider it as primary. This may be another reason the 2 studies differed in term of risk of lameness and specific bedding types.

Prompt identification and treatment of lameness may limit its duration and the prevalence of lame cows by identifying lameness before it progresses, thereby shortening the healing process. Operations that treated lame cows within a day or week of identifying them as lame had a lower prevalence of lameness than operations that waited up to a month to treat cows. These results support previous findings, in which the prevalence and duration of lameness was lower on operations with increased awareness and early identification of lame cows (Clarkson et al., 1996; Gundelach et al., 2013). Interestingly, the current study found that operations that treated lame cows within a few hours after identifying them as lame had a higher prevalence of lame cows than those that treated within a day or a week. Potential reasons for this finding could be that cows were not promptly identified as lame on these operations or that the cows that were identified as lame and treated immediately had already progressed to severe lameness. Routine hoof trimming has been shown to benefit cow hoof health (Blowey, 2005; Mülling et al., 2006), with routine hoof trimmings decreasing the incidence of cow lameness by promoting the early identification and treatment of hoof problems (Manske et al., 2002). In the current study, operations that did not have a hoof trimmer visit during 2013 and those that had a hoof trimmer visit weekly had an increased prevalence of severely lame cows compared with operations that had a hoof trimmer on-farm once a month. To maintain proper hoof health, it is recommended that cows be trimmed 1 or 2 times per year (Shearer and van Amstel, 2001). A study by Van Hertem et al. (2014) showed that trimming resulted in increased prevalence of lameness in cows, and the increased prevalence of lameness was still present 2 mo after trimming. Operations that had an increased frequency of hoof trimming may have been addressing a lameness problem by implementing more frequent trimming.

The use of fans for cooling was associated with a higher prevalence of lameness, which is counterintuitive. Heat stress is associated with increased standing times and increased susceptibility to subacute ruminal acidosis, both of which are associated with increased lameness (Cook et al., 2004, 2007). This study was conducted in spring and early summer, which may have limited any effects of heat stress. The finding of use of fans associated with increased prevalence of lameness was unexpected and may be associated with other unmeasured characteristics of farms that provide heat abatement. 
The prevalence of hock lesions in this study was $17.2 \%$, which was lower than previously reported by Weary and Taszkun (2000), where $72.6 \%$ of cows of farms in British Columbia had some sort of hock lesion. A study that included dairy operations in Wisconsin, Minnesota, New York, Iowa, and Indiana (Fulwider et al., 2007) found a similar prevalence of hock lesions as the current study, with the percentage of cows with no hock lesions ranging from 28.4 to $100.0 \%$, depending on the type of bedding material used. Cook et al. (2016) reported a much higher prevalence of hock lesions, with half the cows $(50.3 \%)$ having some lesions and $12.2 \%$ having severe lesions. A national study conducted in the United States in 2007 (Lombard et al., 2010) found that $23.5 \%$ of cows scored had hock lesions and $3.4 \%$ were severe compared with the 17.2 and $3.6 \%$ in the current study.

Hock lesions can be a result of the quality and type of lying surfaces to which cows have access. The type of operation was associated with hock lesions; conventional operations had a higher percentage of cows with any hock lesions compared with operations that allowed at least some grazing. Rutherford et al. (2008) reported that organic herds had a lower prevalence of hock lesions than nonorganic farms.

Housing type was found to be associated with the prevalence of hock lesions, with cows housed on open/ dry lots having fewer hock lesions than those housed on pasture or in tiestall or freestall barns. Housing cows in open/dry lots was found to be protective against hock lesions, whereas housing cows on pasture, in tiestall/ stanchions, and in freestall barns resulted in an increased prevalence of hock lesions. This finding disagrees with previous studies, where cows on pasture were found to have fewer hock lesions (Bergman et al., 2014). This discrepancy may have resulted from this study being conducted during late spring/early summer, shortly after cows would have been reintroduced to pasture from winter housing. Therefore, the increased prevalence of hock lesions may be a result of winter housing rather than cows being housed on pasture. Hock lesions have been reported to be more prevalent in the spring than in the fall (Rutherford et al., 2008). The outside area used for dry cows in the winter was associated with the presence of any and severe hock lesions. Pasture access for dry cows was associated with a lower prevalence of hock lesions compared with other outside area types such as concrete or open/dry lots, which is in agreement with Barrientos et al. (2013).

The association of hock lesions and tiestalls agrees with previous work, with cows housed in tiestalls having an increased prevalence of hock lesions and swollen knees (Rushen et al., 2008). A study by Zurbrigg et al. (2005) in Ontario, Canada, reported a hock lesion prevalence of $44 \%$ in tiestalls, and most farms had stalls that were shorter than the current recommendations for length and width. Bedding material for lactating cows can affect the prevalence of hock lesions. Sand bedding was found to be beneficial, with cows housed on sand-bedded stalls having a lower prevalence of hock lesions compared with the other bedding types. Multiple studies have highlighted the benefits of using sand bedding, with operations housing cows on sand-bedded stalls having a lower prevalence of hock lesions than those housed on rubber mats or mattresses (Weary and Taszkun, 2000; Lobeck et al., 2011). A study investigating associations between hock injuries and stall design found that farms that used sand had the lowest percentage of severe hock lesions compared with those using manure solids, straw, and sawdust bedding (Lombard et al., 2010).

The finding that few cows had a BCS $\leq 2.25$ suggests that the majority of cows are not excessively thin. When examining farm- and cow-level factors thought to influence the body condition of lactating cows, only the use of sprinklers and misters for cooling cows and the person responsible for balancing rations were associated with the prevalence of thin cows. Numerous studies have shown the detrimental effects of heat stress and how the use of cow cooling methods increases feed intake and may affect BCS (Flamenbaum et al., 1995; Collier et al., 2006; Chen et al., 2016). Also, operations that used a nutritionist to balance rations for lactating cows had a lower percentage of thin cows than those on which the owner or other personnel balanced rations. Because nutritionists appreciate the complex nutritional demands of cows during different stages of lactation, it is understandable that they would be beneficial for balancing rations and minimizing the number of thin cows on an operation. No reports in the literature were found to support this finding; it is intuitive.

Multiple variables met the definition of confounders for the severe lameness and severe hock lesion models in our study. Although the incidence density ratios were evaluated for confounding, further evaluation of the predicted marginal or predicted farm-level prevalences showed that adding the confounding variables to the final model resulted in less than a $1 \%$ change in the predicted severe lameness and hock lesion models for any of the predictor variables. In addition, multicollinearity symptoms were noted upon the addition of many of the individual confounders. For these reasons, no identified confounders were included in the final models.

There are limitations to the methodology of this study. Not all cows on each operation were evaluated due to time constraints of the evaluators. Evaluating a subset of cows rather than the entire herd might have biased the results of this study even though the group 
of cows scored was included as a covariate in all models. Most of the previously reported lameness estimates are based on scoring by one or only a few scorers, whereas this study had a large number of evaluators $(\mathrm{n}=76)$.

Cow evaluations were collected in a single visit that may not have been representative of the cows' condition for the majority of the year. Because this study was national in scope and relied on multiple evaluators, it was not possible to conduct multiple evaluations for every dairy. Additionally, with a subsample of operations participating in the cow evaluation portion of the study, the results might have been biased due to nonresponse as dairies having higher levels of lameness, hock lesions, or thin cows might have decided not to participate in the evaluation.

The breed of cows scored was not recorded in this study, although Holsteins accounted for $>50 \%$ of cows on $91 \%$ of operations. Hoffman et al. (2014) reported a difference in lameness prevalence based on breed, with Jerseys having a lower prevalence than Holsteins. Because the proportion of Holstein herds in this study is similar to the national average, it is likely that breed differences did not bias the overall lameness prevalence estimates.

This study was not able to score all cows on all operations (the gold-standard method of estimating herd-level prevalence). The entire herd was scored on almost half of the operations in this study (47.9\%). When the entire herd could not be evaluated/scored, the pen scored, which was the high production pen on $35.8 \%$ of operations, was recorded and included as a covariate in the analysis. Other studies have also focused on the high-production pen (Espejo et al., 2006; von Keyserlingk et al., 2012). The study by Hoffman et al. (2013) found that the prevalence of all cows in the high-production, low-production, and hospital pens was similar to or higher than (i.e., it overestimated) herd prevalence. When a within-herd prevalence was calculated using only operations where the entire herd was scored, the prevalence was within $0.5 \%$ but only 1 large herd was included.

Another potential limitation of the study was the use of a newly created 3-point scoring system instead of the traditional 5-point locomotion-scoring system. Due to the large number of evaluators and the relative complexity of the 5-point system, it was determined that a simpler method was necessary to conduct this largescale evaluation. One major difference of the 2 scoring systems, in addition to the 2 additional categories, was the focus on the back arch in the 5-point system. The FARM program has also adopted a 3 -point scoring system with similar scoring categories as were used in this study (FARM, 2013). Results from this study will be important benchmarks for producers participating in the FARM program.

Despite the methodological limitations of this study, the findings provide valuable information regarding national estimates for the prevalence of lameness and hock lesions, and BCS on US dairy operations. This study also highlights housing and management practices that are associated with cow lameness, hock lesions, and body condition, allowing the industry to determine which practices are beneficial and which practices should be improved upon.

\section{CONCLUSIONS}

The prevalence of lameness and hock lesions in this study is lower than reported in studies over the past 5 to $10 \mathrm{yr}$, but similar to studies published in 2016. Many associations were identified between operation characteristics and the prevalence of lameness, hock lesions, and thin cows on US dairy operations. Lameness is a multifactorial disease and the findings from this study suggest that cows housed on dirt or pasture, rather than concrete, had a lower prevalence of lameness. Hoof care was also important in reducing lameness: operations that treated lame cows within a day or week or had monthly or twice-monthly visits by the hoof trimmer also had lower lameness prevalence. Using sand as a bedding material for lactating cows protected against both lameness and hock lesions, with the prevalence being lower than on operations that used other bedding materials. The use of cow cooling methods was associated with a higher prevalence of lame cows but a lower prevalence of severely lame cows. Additionally, operations that used a nutritionist to balance rations for lactating cows had fewer thin cows than those on which the owner or other personnel balanced rations. Results from this study highlight management practices that may reduce the prevalence of lameness, hock lesions, and thin cows on operations in the United States.

\section{ACKNOWLEDGMENTS}

Data are from a dissertation submitted to Colorado State University by A. E. Adams in partial fulfilment of requirements for the $\mathrm{PhD}$ degree. Portions of this manuscript were presented at the 2015 ADSA and ASAS Joint Annual Meeting. The authors acknowledge Alejandra Barrientos, Prodeca, Osorno, Chile; Jeffrey Bewley, University of Kentucky, Lexington; Rodrigo Bicalho, Cornell University, Ithaca, NY; Nigel Cook, University of Wisconsin, Madison; Page Dinsmore, Colorado State University, Fort Collins; Frank Garry, Colorado State University, Fort Collins; Ernest Hov- 
ingh, Pennsylvania State University, University Park; Kiyomi Ito, Nanoose Edibles Farm, Parksville, BC, Canada; Dan Leer, Dan Leer Hoof Trimming, Lancaster, PA; Dale Moore, Washington State University, Spokane; Jan Shearer, Iowa State University, Des Moines; Nina von Keyserlingk, University of British Columbia, Vancouver, BC, Canada; Barbara Jones, University of Kentucky, Lexington; and Dan Weary, University of British Columbia, Vancouver, BC, Canada, for assisting in the design and implementation of the 3-point lameness-scoring system, and Matthew Branan, USDAAPHIS-VS CEAH, NAHMS (Fort Collins, CO) for statistical assistance. We thank the dairy producers for participating in the study and the state and federal veterinarians and animal health technicians for conducting the cow evaluations.

\section{REFERENCES}

Barrientos, A. K., N. Chapinal, D. M. Weary, E. Galo, and M. A. von Keyserlingk. 2013. Herd-level risk factors for hock injuries in freestall-housed dairy cows in the northeastern United States and California. J. Dairy Sci. 96:3758-3765.

Bergman, M. A., R. M. Richert, K. M. Cicconi-Hogan, M. J. Gamroth, Y. H. Schukken, K. E. Stiglbauer, and P. L. Ruegg. 2014. Comparison of selected animal observations and management practices used to assess welfare of calves and adult dairy cows on organic and conventional dairy farms. J. Dairy Sci. 97:4269-4280.

Blowey, R. 2005. Factors associated with lameness in dairy cattle. In Pract. 27:154-162.

Booth, C. J., L. D. Warnick, Y. T. Gröhn, D. O. Maizon, C. L. Guard, and D. Janssen. 2004. Effect of lameness on culling in dairy cows. J. Dairy Sci. 87:4115-4122.

Chapinal, N., A. K. Barrientos, M. A. G. von Keyserlingk, E. Galo, and D. M. Weary. 2013. Herd-level risk factors for lameness in freestall farms in the northeastern United States and California. J. Dairy Sci. 96:318-328.

Chapinal, N., Y. Liang, D. M. Weary, Y. Wang, and M. A. G. von Keyserlingk. 2014. Risk factors for lameness and hock lesions in Holstein herds in China. J. Dairy Sci. 97:4309-4316.

Chen, J. M., K. E. Schütz, and C. B. Tucker. 2016. Cooling cows efficiently with water spray: Behavioral, physiological, and production responses to sprinklers at the feed bunk. J. Dairy Sci. 99:4607-4618. https://doi.org/10.3168/jds.2015-10714.

Clarkson, M. J., D. Y. Downham, W. B. Faull, J. W. Hughes, F. J. Manson, J. B. Merrit, R. D. Murray, W. B. Russell, J. E. Sutherst, and W. R. Ward. 1996. Incidence and prevalence of lameness in dairy cattle. Vet. Rec. 138:563-567.

Collier, R. J., G. E. Dahl, and M. J. VanBaale. 2006. Major advances associated with environmental effects on dairy cattle. J. Dairy Sci. 89:1244-1253.

Cook, N. B. 2003. Prevalence of lameness among dairy cattle in Wisconsin as a function of housing type and stall surface. J. Am. Vet. Med. Assoc. 223:1324-1328.

Cook, N. B. 2013. Don't be so lame-Time to implement solutions to sore feet. Pages 77-87 in Western Dairy Management Conference. Reno, Nevada. Accessed April 2016. http://wdmc. org/2013/Don\%27t\%20be\%20so\%20lame\%20-\%20Time\%20to\%20 Implement\%20Solutions\%20to\%20Sore\%20Feet.pdf.

Cook, N. B., J. P. Hess, M. R. Foy, T. B. Bennett, and R. L. Brotzman. 2016. Management characteristics, lameness, and body injuries of dairy cattle housed in high-performance dairy herds in Wisconsin. J. Dairy Sci. 99:5879-5891.
Cook, N. B., R. L. Mentink, T. B. Bennett, and K. Burgi. 2007. The effect of heat stress and lameness on time budgets of lactating dairy cows. J. Dairy Sci. 90:1674-1682.

Cook, N. B., K. V. Nordlund, and G. R. Oetzel. 2004. Environmental influences on claw horn lesions associated with laminitis and subacute ruminal acidosis (SARA) in dairy cows. J. Dairy Sci. 87:E36-E46.

Cornell University. 2009. Hock Assessment for Cattle, Cornell Cooperative Extension (adapted from James Nocek). Accessed Apr. 10, 2016. https://ecommons.cornell.edu/bitstream/ handle $/ 1813 / 36913 /$ hockscore. $p d f$ ?sequence $=1 \&$ is Allowed $=y$.

Elanco Animal Health. 2009. The 5-point body condition scoring system. Accessed Apr. 10, 2016. https://www.elanco.us/pdfs/ ai10752-body-condition-score-insert.pdf.

Espejo, L. A., M. I. Endres, and J. A. Salfer. 2006. Prevalence of lameness in high-producing Holstein cows housed in freestall barns in Minnesota. J. Dairy Sci. 89:3052-3058.

FARM. 2013. Farmer's Assuring Responsible Management Animal Care Reference Manual, Accessed Apr. 10, 2016. http://www. nationaldairyfarm.com/sites/default/files/FARM_manual_2013_ WEB.pdf

Ferguson, J. D., D. T. Galligan, and N. Thomsen. 1994. Principal descriptor of body condition score in Holstein cows. J. Dairy Sci. 77:2695-2703.

Flamenbaum, I., D. Wolfenson, P. L. Kunz, M. Maman, and A. Berman. 1995. Interactions between body condition at calving and cooling of dairy cows during lactation in summer. J. Dairy Sci. 78:2221-2229.

Fulwider, W. K., T. Grandin, D. J. Garrick, T. E. Engle, W. D. Lamm, N. L. Dalsted, and B. E. Rollin. 2007. Influence of free-stall base on tarsal joint lesions and hygiene in dairy cows. J. Dairy Sci. 90:3559-3566.

Garbarino, E. J., J. A. Hernandez, J. K. Shearer, C. A. Risco, and W. W. Thatcher. 2004. Effect of lameness on ovarian activity in postpartum Holstein cows. J. Dairy Sci. 87:4123-4131.

Gillund, P., O. Reksen, Y. T. Grohn, and K. Karlberg. 2001. Body condition related to ketosis and reproductive performance in Norwegian dairy cows. J. Dairy Sci. 84:1390-1396.

Gundelach, Y., T. Schulz, M. Feldmann, and M. Hoedemaker. 2013. Effects of increased vigilance for locomotion disorders on lameness and production in dairy cows. Animals (Basel) 3:951-961.

Haskell, M. J., L. J. Rennie, V. A. Bowell, M. J. Bell, and A. B. Lawrence. 2006. Housing system, milk production, and zero-grazing effects on lameness and leg injury in dairy cows. J. Dairy Sci. 89:4259-4266.

Hernandez, J. A., E. J. Garbarino, J. K. Shearer, C. A. Risco, and W. W. Thatcher. 2005. Comparison of mil, yield in dairy cows associated with different degrees of lameness. J. Am. Vet. Med. Assoc. 227:1292-1296.

Hernandez, J. A., J. K. Shearer, and D. W. Webb. 2001. Effect of lameness on the calving-to-conception interval in dairy cows. J. Am. Vet. Med. Assoc. 218:1611-1614.

Hoedemaker, M., D. Prange, and Y. Gundelach. 2009. Body condition change ante- and postpartum, health and reproductive performance in German Holstein cows. Reprod. Domest. Anim. 44:167173.

Hoffman, A. C., D. A. Moore, J. R. Wenz, and J. Vanegas. 2013. Comparison of modeled sampling strategies for estimation of dairy herd lameness prevalence and cow-level variables associated with lameness. J. Dairy Sci. 96:5746-5755.

Hoffman, A. C., J. R. Wenz, J. Vanegas, and D. A. Moore. 2014. Estimated prevalence of lameness in 53 Northwest US dairy herds. Bovine Pract. 48:89-94.

Ingvartsen, K. L. 2006. Feeding- and management-related disease in the transition cow: Physiological adaptation around calving and strategies to reduce feeding-related diseases. Anim. Feed Sci. Technol. 126:175-213.

Juarez, S. T., P. H. Robinson, E. J. DePeters, and E. O. Price. 2003. Impact of lameness on behavior and productivity of lactating Holstein cows. Appl. Anim. Behav. Sci. 83:1-14. 
Lobeck, K. M., M. I. Endres, E. M. Shane, S. M. Godden, and J. Fetrow. 2011. Animal welfare in cross-ventilated, compost-bedded pack, and naturally ventilated dairy barns in the upper Midwest. J. Dairy Sci. 94:5469-5479.

Lombard, J. E., C. B. Tucker, M. A. G. von Keyserlingk, C. A. Kopral, and D. M. Weary. 2010. Associations between cow hygiene, hock injuries, and free stall usage on U.S. dairy farms. J. Dairy Sci. 93:4668-4676.

Manske, T., J. Hultgren, and C. Bergsten. 2002. The effect of claw trimming on the hoof health of Swedish dairy cattle. Prev. Vet. Med. 54:113-129.

Markusfeld, O. 1985. Relationship between overfeeding, metritis and ketosis in high yielding dairy cows. Vet. Rec. 116:489-491.

Mülling, C. K. W., L. Green, Z. Barker, J. Scaife, J. Amory, and M. Speijers. 2006. Risk factors associated with foot lameness in dairy cattle and a suggested approach for lameness reduction. World Buiatrics Congress. Nice, France.

Nash, C. G. R., D. F. Kelton, T. J. DeVries, E. Vasseur, J. Coe, J. C Zaffino Heyerhoff, V. Bouffard, D. Pellerin, J. Rushen, A. M. de Passillé, and D. B. Haley. 2016. Prevalence of and risk factors for hock and knee injuries of dairy cows in tiestall housing in Canada. J. Dairy Sci. 99:6494-6506.

O'Callaghan, K. A., P. J. Cripps, D. Y. Downham, and R. D. Murray 2003. Subjective and objective assessment of pain and discomfort due to lameness in dairy cattle. Anim. Welf. 12:605-610.

Roche, J. R., and D. P. Berry. 2006. Periparturient climatic, animal, and management factors influencing the incidence of milk fever in grazing systems. J. Dairy Sci. 89:2775-2783.

Roche, J. R., N. C. Friggens, J. K. Kay, M. W. Fisher, K. J. Stafford and D. P. Berry. 2009. Invited review: Body condition score and its association with dairy cow productivity, health, and welfare. J. Dairy Sci. 92:5769-5801.

Rushen, J., A. M. de Passillé, M. A. G. von Keyserlingk, and D. M. Weary. 2008. The Welfare of Dairy Cattle. Springer, Dordrecht, the Netherlands.

Rushen, J., D. Haley, and A. M. Passillé. 2007. Effect of softer flooring in tiestalls on resting behavior and leg injuries of lactating cows. J. Dairy Sci. 90:3647-3651.

Rutherford, K. M., F. M. Langford, M. C. Jack, L. Sherwood, A. B. Lawrence, and M. J. Haskell. 2008. Hock injury prevalence and associated risk factors on organic and nonorganic dairy farms in the United Kingdom. J. Dairy Sci. 91:2265-2274.

Shearer, J. K., and S. R. van Amstel. 2001. Functional and corrective claw trimming. Vet. Clin. North Am. Food Anim. Pract. 17:53-72.

Solano, L., H. W. Barkema, E. A. Pajor, S. Mason, S. J. LeBlanc, J. C. Zaffino Heyerhoff, C. G. R. Nash, D. B. Haley, E. Vasseur, D. Pellerin, J. Rushen, A. M. de Passillé, and K. Orsel. 2015. Prevalence of lameness and associated risk factors in Canadian HolsteinFriesian cows housed in freestall barns. J. Dairy Sci. 98:6978-6991.
Sprecher, D. J., D. E. Hostetler, and J. B. Kaneene. 1997. A lameness scoring system that uses posture and gait to predict dairy cattle reproductive performance. Theriogenology 47:1179-1187.

USDA. 2013. Cattle Report. National Agricultural Statistical Services, Agricultural Statistics Board. USDA. Ithaca, NY.

USDA. 2014. Dairy 2014 questionnaires. Accessed Apr. 10, 2016. https://www.aphis.usda.gov/aphis/ourfocus/animalhealth/ monitoring-and-surveillance/nahms/dairy_questionnaires.

Van Hertem, T., Y. Parmet, M. Steensels, E. Maltz, A. Antler, A. A Schlageter-Tello, C. Lokhorst, C. E. B. Romanini, S. Viazzi, C. Bahr, D. Berckmans, and I. Halachmi. 2014. The effect of routine hoof trimming on locomotion score, ruminating time, activity, and milk yield of dairy cows. J. Dairy Sci. 97:4852-4863.

Vanegas, J. L., M. Overton, S. L. Berry, and W. M. Sischo. 2006. Effect of rubber flooring on claw health in lactating dairy cows housed in free-stall barns. J. Dairy Sci. 89:4251-4258.

von Keyserlingk, M. A. G., A. Barrientos, K. Ito, E. Galo, and D. M. Weary. 2012. Benchmarking cow comfort on North American freestall dairies: Lameness, leg injuries, lying time, facility design, and management for high-producing Holstein dairy cows. J. Dairy Sci. 95:7399-7408.

Warnick, L. D., D. Janssen, C. L. Guard, and Y. T. Gröhn. 2001. The effect of lameness on milk production in dairy cows. J. Dairy Sci. 84:1988-1997.

Weary, D. M., and I. Taszkun. 2000. Hock lesions and free-stall design. J. Dairy Sci. 83:697-702.

Westin, R., A. Vaughan, A. M. de Passillé, T. J. DeVries, E. A. Pajor, D. Pellerin, J. M. Siegford, E. Vasseur, and J. Rushen. 2016. Lying times of lactating cows on dairy farms with automatic milking systems and the relation to lameness, leg lesions, and body condition score. J. Dairy Sci. 99:551-561.

Whay, H. R., D. C. J. Main, L. E. Green, and A. J. F. Webster. 2003 Animal-based measures for the assessment of welfare state of dairy cattle, pigs and laying hens: Consensus of expert opinion. Anim. Welf. 12:205-217.

Wildman, E. E., G. M. Jones, P. E. Wagnar, H. F. Trout, and T. N. Lesch. 1982. A dairy cow body condition scoring system and its relationship to selected production variables in high producing Holstein dairy cattle. J. Dairy Sci. 65:495-501.

Zaffino Heyerhoff, J. C., S. J. LeBlanc, T. J. DeVries, C. G. Nash, J Gibbons, K. Orsel, H. W. Barkema, L. Solano, J. Rushen, A. M. de Passillé, and D. B. Haley. 2014. Prevalence of and factors associated with hock, knee, and neck injuries on dairy cows in freestall housing in Canada. J. Dairy Sci. 97:173-184.

Zurbrigg, K., D. Kelton, N. Anderson, and S. Millman. 2005. Tie-stal design and its relationship to lameness, injury, and cleanliness on 317 Ontario dairy farms. J. Dairy Sci. 88:3201-3210. 